\title{
Remote sensing of surface roughness and top soil moisture of bare tilled soil with an X-band radar
}

\author{
A. J. Koolen, F. F. R. Koenigs and W. Bouten \\ Department of Soils and Fertilizers, Agricultural University, De Dreijen 3, Wage- \\ ningen, the Netherlands
}

Accepted: 23 April 1979

Key words: remote sensing, soil surface roughness, top soil moisture, radar

\section{Summary}

Radar in an aeroplane or a satellite can take measurements from bare agricultural soil. It can do so day and night and under practically all weather conditions. Such measurements highly reflect soil surface roughness and top soil moisture content. Using a ground-based radar with a single frequency in the $\mathrm{X}$-band $(3 \mathrm{~cm}$ wavelength) and six bare-soil experimental fields we investigated mapping feasibility of soil surface roughness and top soil moisture content. The experimental fields were intended to cover the broad range of bare-soil appearances that occur in agricultural practice. Therefore, the field treatments included a number of tillage types, several degrees of soil structure change that normally occur after tillage, and different top soil moisture contents. Different angles between the ray beam and the irradiated land part (grazing angles) were investigated. Radar return $(\gamma)$-grazing angle curves had shapes which were entirely determined by soil surface roughness. The levels of these curves depended on moisture content. Although it appeared that this type of radar has limited discrimination ability, it could already be concluded that mapping of roughness and moisture may be possible under certain conditions.

\section{Introduction}

The weather in the Netherlands and in many other parts of the world is such that the observation of the earth's surface from the air is often impossible when sensors are used working in the visible and the infrared. Radar, on the other hand, is independent of daylight and practically independent of the weather. Because of this 'all weather' capability it is useful to investigate the mapping possibilities of radar. This paper deals with mapping feasibility of top soil moisture and surface roughness of bare soil with an X-band radar.

Radar emits microwaves at a given energy level and measures the energy of the 
microwaves that are received back by the radar. The ratio of the received energy to the emitted energy can be expressed by the return parameter $\gamma$ the units of which (decibels) are defined according to a certain logarithmic scale (Moore, 1975; de Loor, 1976; Attema, 1978). When a radar in an aeroplane or a satellite emits a beam of microwaves to a terrestrial soil surface, this soil surface will partly absorb and partly reflect these waves. Reflection is partly in a direction according to mirror reflection, and partly in other directions (scattering). The energy of the microwaves that are reflected back in the direction of the radar (the radar backscatter) is measured by the radar. If a rather narrow radar beam irradiates a bare soil surface part, and the irradiated area is large relative to the roughness elements of the surface, then the measured $\gamma$ will depend on:

- wavelength of the microwaves;

- angle between the centre line of the beam of microwaves and the irradiated land part;

- polarization of the emitted and received microwaves;

- roughness of the soil surface;

- amount and distribution of moisture in the soil profile to a depth of about one wavelength.

In view of the above, the following question is obvious. Can radar in an aeroplane or a satellite be used to measure and to map moisture content and/or surface roughness of a bare soil, and, if this appears to be essentially possible, which wavelength, polarization and radar beam direction is optimal for this? If a single wavelength, polarization and beam direction would give information with too little accuracy, the question may be extended: which combinations of wavelengths and/ or polarization directions and/or ray beam directions will give most information at least costs? Though some soil mapping radars are operational yet, or will be soon, these questions are still only partly answered and research on this is being carried out (Attema, 1978). For instance, at the start of 1978, a joint project on radar measurements of bare tilled soil was initiated by the Technical University in Delft, the Physics Laboratory TNO in The Hague, and the Agricutural University in Wageningen. This project concentrated more on surface roughness and less on wavelength variation than other similar projects (Batlivala \& Ulaby, 1977; Ulaby \& Craig Dobson, 1978) did.

\section{Experimental set-up}

The 1978 experiments from this joint project were located at the experimental farm 'De Bouwing' in Randwijk. The radar was suspended in a 10-m high vertical tower that could be moved along rails. At one side of the rails were 6 experimental fields, $15 \times 20 \mathrm{~m}^{2}$ each (Fig. 1). The radar beam centre line was always in a vertical plane perpendicular to the rails. The radar was movable vertically and could be rotated around a horizontal axis parallel to the rails. The angle between the beam centre line and the horizontal (grazing angle) could be varied from $10^{\circ}$ to $80^{\circ}$ in $10^{\circ}$ increments. Field sides perpendicular to the rails had to be at least $14 \mathrm{~m}$ to allow this range of angles. To keep the necessary soil sampling out of the 


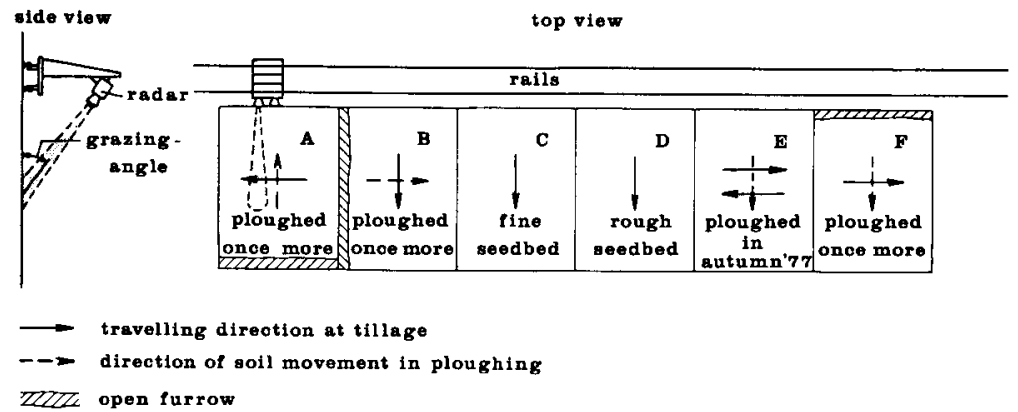

Fig. 1. Radar set-up and lay-out of the experimental fields.

radar field of view, these sides were not $14 \mathrm{~m}$, but $20 \mathrm{~m}$, so that a $6-\mathrm{m}$ wide strip was available for soil sampling. Trial field sides parallel to the rails were $15 \mathrm{~m}$ long, enabling to determine $\gamma$ as a mean of 70 independent measurements for one field and one beam direction. This was necessary to reach a sufficient high accuracy. The radar used worked at a wavelength of $3 \mathrm{~cm}$ (X-band). Three different polarizations of the microwaves were possible;

$\mathrm{HH}$ (horizontal for the emitted and the received waves)

VV (vertical for the emitted and the received waves)

$\mathrm{VH}$ (vertical for the emitted and horizontal for the received waves).

Each $\gamma$ determination was always duplicated.

In building and using the radar set-up use could be made of experience from a similar set-up for other purposes (van Kasteren \& Smit, 1977). This was not the case for the arrangement and treatment of the bare soil experimental fields. We wanted to examine radar discrimination under practical conditions. Therefore, we had to cope with the following two problems:

- How can the most important appearances of bare tilled soil be simulated in the trial fields?

- How should one collect information on surface roughness and soil moisture content from these fields, in order that a meaningful interpretation of the $\gamma$ determinations will be possible?

\section{Realizing the most important appearances of bare arable land}

To obtain the most important appearances of bare agricultural soil, the following factors must be varied within wide ranges

- tillage type: the most frequent tillage types from agricultural practice should be represented;

- for each selected tillage type: degree of soil structure change due to weather influences etc. after tillage;

- for each selected tillage type and step of structure change: the moisture condition of the top layer of the soil as it can vary in consequence of precipitation, evaporation, etc. 


\section{Tillage types}

After harvest the land is covered by plant residues, or bare, as after the harvest of potatoes, sugar beets etc. Such bare soil may have a very characteristic appearance, for example strips of fine sieved soil alternating with ruts. The first tillage operation after the harvest is mostly a shallow one, and is named stubble cultivation. Some time after the stubble cultivation the so-called primary tillage operation reaching much deeper will follow. Finally, after another elapse of time, a seedbed preparation will be performed, mostly at a very shallow working depth. In an area, these three conditions can exist side by side at the same time.

The above tillage system is rather universal. On the contrary, the way in which it is carried out can strongly differ from one area to another. This is connected with the level of technology, soil type, the sensitivity to erosion of an area, the climate, the crops that are grown (Davies et al., 1972; Bernacki et al., 1972). In addition, the way in which tillage is carried out may also vary within an area. Concentrating on the Netherlands, for example, it appears that

- in stubble cultivation one uses multiple-furrow one-way ploughs, implements with tines (cultivators) or discs. The kind of implement is decisive for the soil surface geometry that will be obtained;

- primary tillage uses multiple-furrow one-way ploughs or multiple-furrow halfturn ploughs. The plough type used is always reflected in the soil surface geometry that results, because of the absence of planes of symmetry in a ploughed soil beam; - the implements used in seedbed preparation may or may not leave distinct ridges. The ridges can vary in width and may be straight or zigzagging;

- the situation is extra complicated because within one tilled field more tillage directions may exist, which are perpendicular or even oblique to each other.

Of course, uniformity is better if the area to be mapped is selected smaller. For instance, if attention is confined to northwest Groningen, bare soil appearance in winter mainly involves (a) soil, ploughed with a multiple-furrow half-turn plough, and (b) rough seedbeds showing not much ridge formation. However, there are also areas in which short distance variations are always large, for example GoereeOverflakkee.

The design of the radar experimental fields incorporated seedbeds, ploughed land, and different ploughing directions. The radar measurements started about 1 June 1978. In the month of May before, the 6 trial fields were prepared, each with a different tillage type. Fig. 1 gives a schematic lay-out of these fields, along with their tillage directions, etc. The parcel in which the small fields were prepared, was used in 1977 for growing winter wheat with clover as a green manure crop. The stubble was ploughed (ploughing depth ca. $25 \mathrm{~cm}$ ) on 24 November 1977 with a two-furrow half-turn plough that was equipped with disc coulters and skim coulters. This tilth was maintained in field E. Fields A, B and F were ploughed once more on 18 May 1978 at a ploughing depth of ca. $25 \mathrm{~cm}$. This was done with twofurrow one-way ploughs. The plough was right-handed for fields $A$ and $F$, and left-handed for field B. The soil in the lower part of the arable layer was still very wet when $\mathrm{A}, \mathrm{B}$ and $\mathrm{F}$ were prepared. Field $\mathrm{C}$ was changed to a fine seedbed on 11 May 1978 with a p.t.o. (power take-off) driven rotary harrow. Working depth 
was $7-8 \mathrm{~cm}$. After this operation, unevennesses were removed with a hand-rake. Field D was tilled on 18 May with a rigid tine cultivator, so that a rough seedbed was obtained. Centre-to-centre distance between the cultivator tine paths was $25 \mathrm{~cm}$, and working depth was $10-15 \mathrm{~cm}$.

\section{Steps of structure change after tillage}

Immediately after a tillage operation a process of soil structure change will start in the structure that is made by the tillage operation. This change may comprise:

- settlement of the arable layer

- an increasing weed occupation

- slaking (flattening of the soil surface relief due to rain and wetness)

- water erosion (carrying off of soil particles through overland flow of water)

- wind erosion (carrying off of soil particles by the wind).

The speed of the structure change varies with time and depends on tillage type, soil type, weather, etc. For the kind of trial fields we are considering it is desirable that the siructure change can be controlled. One should be able to stop the process of structure change, as well as to induce a high rate of change. This could be achieved by the following:

- performing the tillage operations on the trial fields 2-3 weeks before the radar measurements started. It was assumed that the rate of settlement had slowed down to a negligable value in these weeks;

- controlling weeds chemically;

- the choice of the soil type (Randwijk clay loam, $\mathrm{pH}_{\mathrm{Kal}} 6.2$, humus content $1.8 \%, \mathrm{CaCO}_{3}$ content $0.1 \%$, specific density 2.69 ). This soil is not very sensitive to slaking and water and wind erosion;

- letting the soil structure changing process proceed by slaking. Because the soil used is only little sensitive to slaking, it was expected that the slaking would require much more rain than the natural rainfall in the experimental period, so that slaking should be realized mainly by artificial rainfall. Of course, this is ideal for controlling the degree of slaking.

As a first approximation it may be assumed that the degree of slaking at a given point of time is entirely determined by the amount of rainfall between time of the last tillage operation and the point of time under consideration (but there is also effects of the impact action of the rain, and the degree to which the soil top layer is soaked during the rainfall). Fig. 2 shows the cumulative rainfall during the experimental period plotted against the sequential numbers of the days on which radar measurements were taken. Also, the dates of measurement are assigned to the numbers. Fig. 2 clearly shows that, roughly speaking, four steps of slaking were realized. The former two steps were obtained due to a lucky distribution of the natural rainfall. The latter two steps were adjusted by artificial rainfall, between the sequential numbers 16 and 17, and between 21 and 22, respectively. The artificial raining was done with a normal Sprinkler irrigation equipment with a rain capacity of $8 \mathrm{~mm} /$ hour.

Because degree of slaking also depends on the starting situation, i.e. the soil tilth, degrees of slaking are not equal for all fields at a given step. 


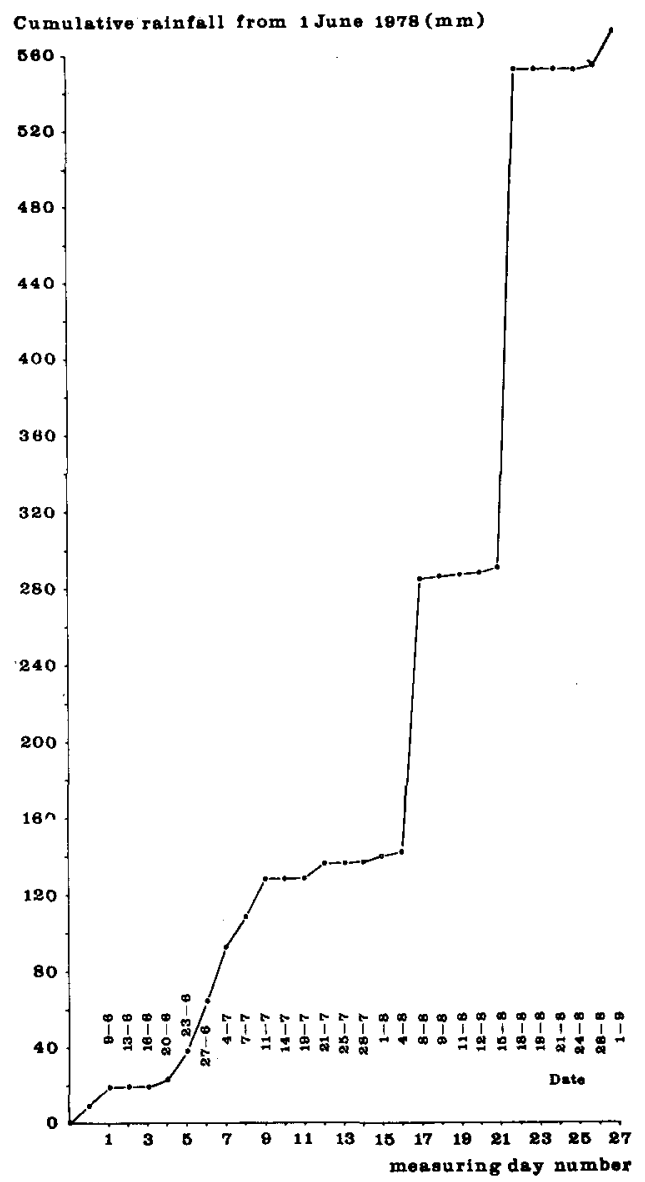

Fig. 2. Cumulative rainfall in the experimental period.

\section{The moisture conditions}

The moisture conditions of a soil may vary strongly. An extreme situation is soil being entirely flooded or carrying water pools. When a wet soil is drying, this progresses more or less irregularly, and the higher parts of the suface relief may exhibit light coloured lumps, or light spots may be recognized in the surface paris that are directed toward the sun. A very dry soil has a uniform light colour. In the experiments it was attempted to take radar measurements at 4-8 different moisture conditions ranging from dry to wet for each step of slaking. The moisture variations required for this, were achieved by natural evaporation and rainfall.

\section{Measurement of roughness and moisture content}

In order to be able to relate the radar measurements with the roughness and the moisture condition of the soil, the surface roughness and the soil moisture condition should have been determined for each radar measuring day. The question 
of which roughness measurements and moisture measurements are desired here, can only be answered if it is known how microwaves react to soil. This knowledge is not sufficiently available yet, and, therefore, a number of measurements were selected more or less arbitrarily. From them, the following ones will be treated here (a) visual rating of slaking of the topsoil, and (b) volumetric water content of the soil clods, or soil clod parts that are present in the topsoil to a depth of $4 \mathrm{~cm}$ (which is nearly equal to the radar wavelength).

\section{Visual classification of the degree of slaking}

The degree of slaking of each field was classified at several points of time using a visual classification method developed at the Institute for Soil Fertility in Haren (Groningen) (Boekel, 1976). The method is that the field for which the degree of slaking is to be determined is compared with a set of standard photographs. Ten standard degrees of slaking are defined, and labeled by the so-called slaking values: 10 (unslaked), 9, 8, ., 1 (entirely slaked). There are sets of standard photographs for ploughed land and for seedbeds. The classification results are presented as dots in the slaking value-cumulative rainfall graph of Fig. 3. On the basis of these dots curves were drawn. The degree of slaking for each measuring day and each field can be read from these curves. Fig. 3 shows the following.

- Visually, no differences in slaking between the fields A, B and F could be observed.

- Between the seedbed preparations and the start of the measuring period, the seedbeds were already slaked to a slight degree.

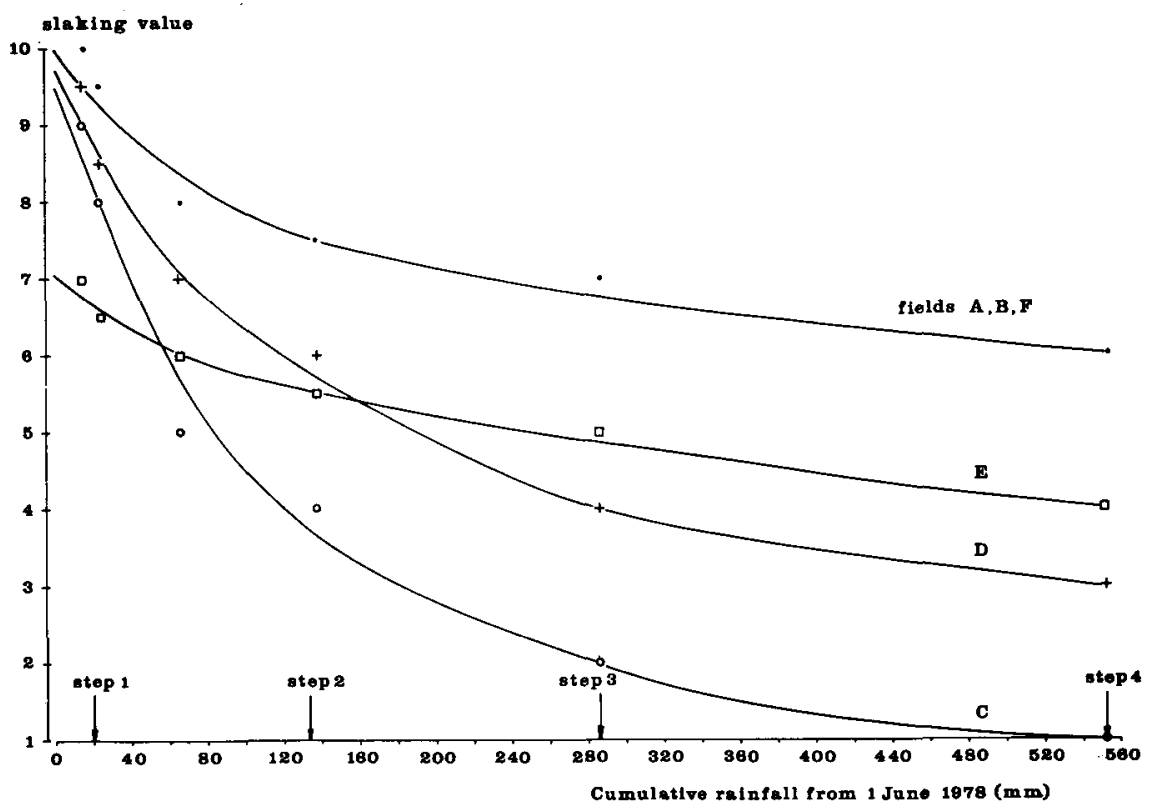

Fig. 3. Slaking value as a function of cumulative rainfall. 


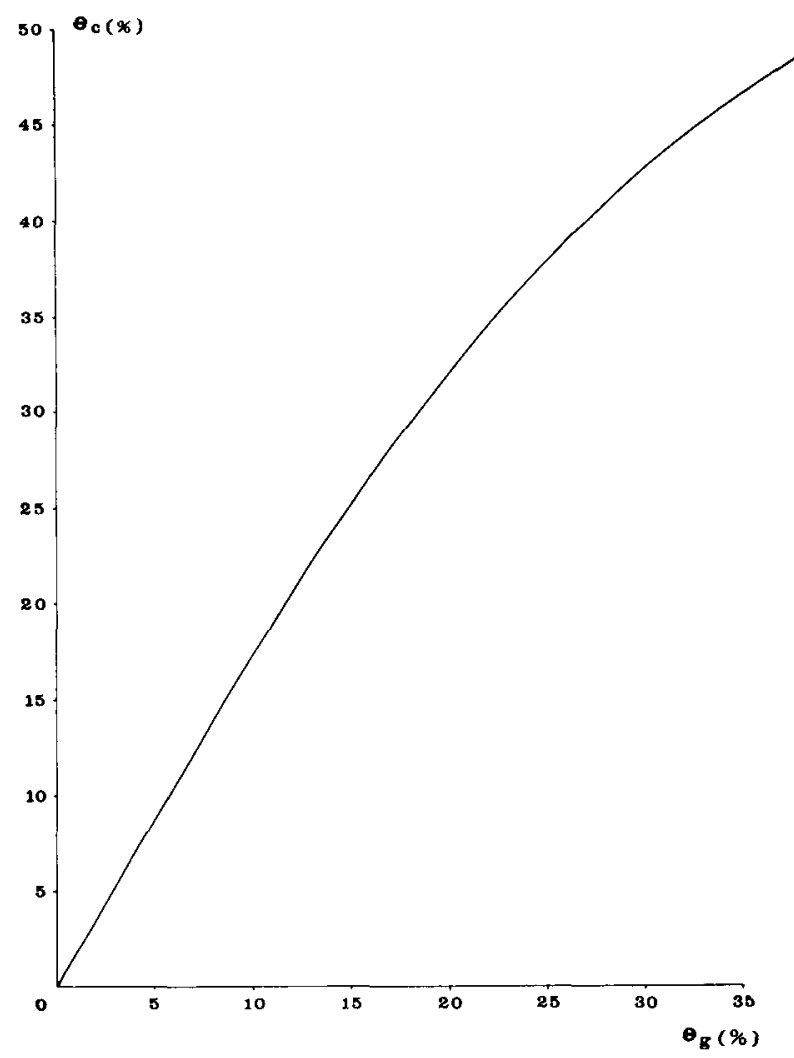

Fig. 4. Relationship between moisture content by weight $(\Theta \mathrm{g})$ and volumetric clod moisture content $(\Theta c)$ applying to the topsoil.

- In the measuring period the fine seedbed was entirely, and the rough seedbed almost entirely slaked.

- Field E shows that much slaking has already occurred between 24 November 1977 (ploughing date of E) and 1 June 1978. The field was slaked further in the measuring period, but it is clear that for such fields having a very rough initial relief, it would be difficult to reach the totally slaked condition.

- From a comparison of the right curve end for A, B and F with the initial part of the curve for $\mathrm{E}$ it appears that slaking effect was greater in the measuring period than between 24 November 1977 and 1 June 1978 (in fact, the difference is even larger because flattening in winter was enhanced by frost action).

Volumetric clod moisture content in the top $4 \mathrm{~cm}$

Each measuring day, soil moisture contents by weight $\left(\Theta_{g}\right)$ were determined from each trial field for the $0-4 \mathrm{~cm}$ layer (if there was a thin top layer with a highly deviating moisture content, that layer was sampled instead of the $0-4 \mathrm{~cm}$ layer). Depending on soil hardness and wetness, sampling was done by collecting soil clods by hand, or using a core sampler, or by sawing out soil pieces. Moisture content was always determined as a mean of 10 independent samples. 
From each moisture content by weight a volumetric clod moisture content $\left(\Theta_{\mathrm{c}}\right)$ was determined using the assumption of the $\Theta_{\mathrm{c}}-\Theta_{\mathrm{g}}$ relation not being affected by soil tillage for this type of soil, thus assuming that this relation is equal for each field at any point of time. The $\Theta_{\mathrm{c}}-\Theta_{\mathrm{g}}$ relation may be considered to be composed of 3 curve parts.

Part 1: at moisture contents lower than the shrinkage limit. The relation is a straight line and could easily be determined by measuring dry bulk volume weight of rather dry clods by the paraffin method (de Boodt, 1967). It was measured that dry bulk volume weight was $1.73 \mathrm{gr} / \mathrm{cm}^{3}$ giving

$$
\Theta_{\mathrm{c}}=1.73 \Theta_{\mathrm{g}} \text {. }
$$

Part 3: at moisture contents being such high that all air within the clods must be considered to be locked. Volumetric air content was determined at several points of time and $4 \%$ was the lowest value found. The following relationship can be derived for the $4 \%$ air condition:

$$
\Theta_{c}=\frac{96 \times 2.69 \times \Theta_{\mathrm{g}}}{100+2.69 \times \Theta_{\mathrm{g}}}
$$

Part 2: here, changes in air content occur, as well as swelling and shrinking. The $\Theta_{\mathrm{c}}-\Theta_{\mathrm{g}}$ relation was measured empirically on moist clods using the paraffin method. The result was

$$
\Theta_{\mathrm{e}}=-0.0208 \Theta_{\mathrm{g}}{ }^{2}+2.1133 \Theta_{\mathrm{g}}-1.7753 \text {. }
$$

Fig. 4 gives these three parts as one smooth curve. With this curve, a $\Theta_{c}$ value can be assigned to any $\Theta_{\mathrm{g}}$ measured in the experimental period.

\section{A discussion on the radar measurements from an agricultural point of view}

From the measuring results it appeared that $\gamma_{\mathrm{VV}}$ ( $\gamma$ for the VV polarization), $\gamma_{\mathrm{IIH}}$ and $\gamma_{\mathrm{VF}}$ are highly correlated to each other. Hence, in general, measuring more than one polarization did not result in more discrimination. (An exeption to this was the very slaked fine seedbed at small grazing angles. In that case, discrimination was shown to be favoured when using both $\gamma_{V H}$ and $\gamma_{V V}$.) All $\gamma$ values in the following discussion are $\gamma_{v V}$ values.

The relationship between $\gamma_{\mathrm{VV}}$ and the grazing angle was measured for each field on each radar measuring day. Then, such relationship is valid for a given field, a given degree of slaking, and a given soil moisture content, and can be represented graphically as a curve. Fig. 5 gives a number of such curves, namely those for the wettest, and those for the driest condition within each step of slaking for each field. Each row of graphs applies to a given field, and each column to a given step of slaking. Smoothed slaking values for each step of slaking and each field are read from Fig. 3, and presented in Table 1 (in this table, smoothed standard deviations of surface heights from relief measurements are also given). Fig. 5 shows the following.

- A change in moisture content makes the level of the curves shift, but is not reflected in curve shape. It appears that curve level tends to be higher as moisture 

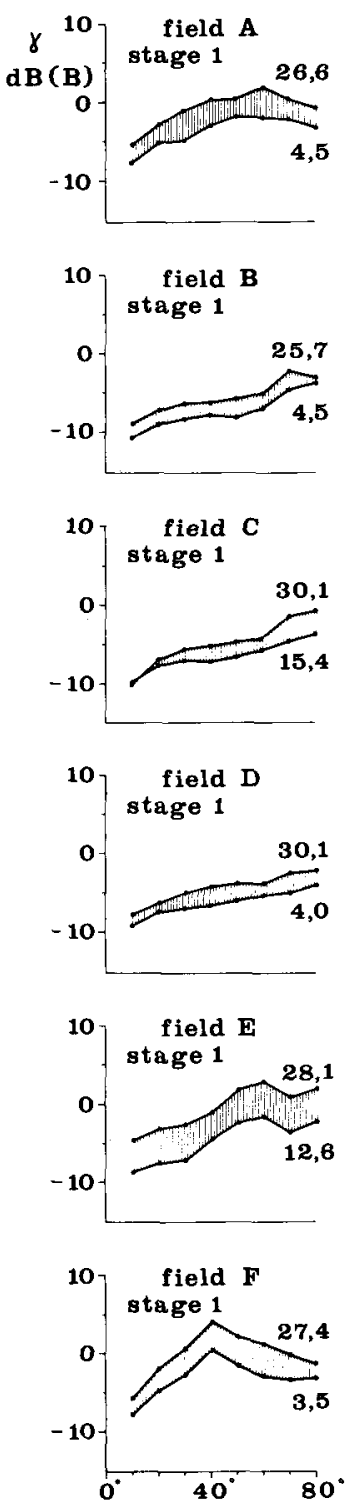

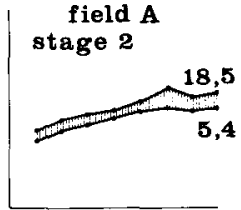

field B stage 2

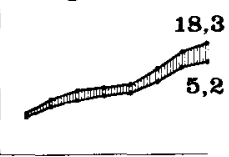

field C stage 2

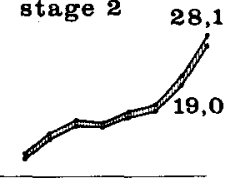

field $D$ stage 2

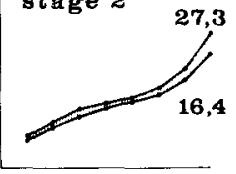

field $\mathrm{E}$ stage 2

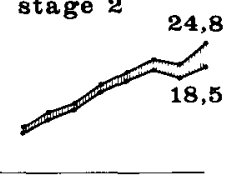

field $F$ stage 2

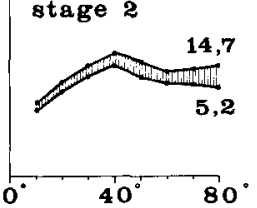

field $A$

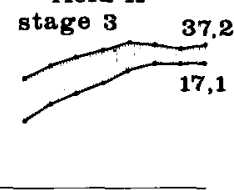

field $B$
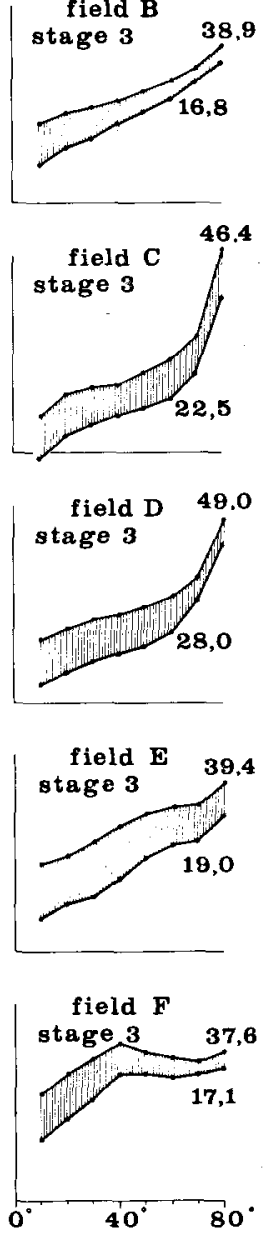

field A

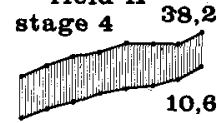

field $B$ stage 4
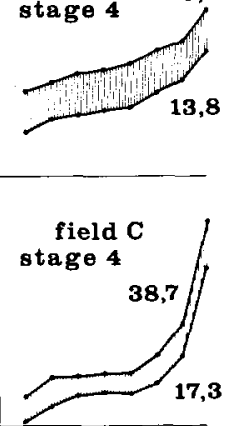

field D

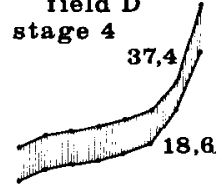

field $E$ stage

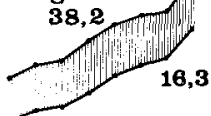

field $F$

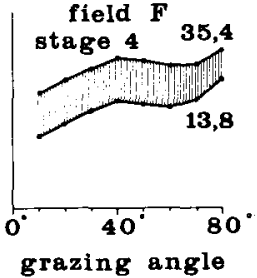

Fig. 5. Radar measuring results. The volumetric clod moisture content at which a curve was determined is given by the number at each curve.

content is higher, and that, in general, curve level-moisture content relationship is specific for a given field and step of slaking. This is demonstrated in Fig. 6, which is a cross section at the $70^{\circ}$ grazing angle through all measured curves for fields $A$ and $C$. The points of intersection are plotted against $\Theta_{c}$. It may be assumed 
Table 1. Smoothed $\delta$ values in $\mathrm{cm}(\delta=$ standard deviation of surface height) and smoothed slaking values (SV).

\begin{tabular}{|c|c|c|c|c|c|c|c|c|}
\hline \multirow[t]{2}{*}{ Step of slaking } & \multicolumn{2}{|c|}{ Fields A, B, F } & \multicolumn{2}{|c|}{ Field C } & \multicolumn{2}{|c|}{ Field D } & \multicolumn{2}{|c|}{ Field E } \\
\hline & $\delta$ & $S V$ & $\delta$ & $\mathrm{S} \mathrm{V}$ & $\delta$ & $S \mathrm{~V}$ & $\delta$ & $S \mathrm{~V}$ \\
\hline 1 & 6.1 & 9.4 & 0.80 & 8.2 & 1.38 & 8.8 & 2.93 & 6.7 \\
\hline 2 & 5.3 & 7.5 & 0.76 & 3.7 & 1.25 & 5.8 & 2.78 & 5.5 \\
\hline 3 & 4.4 & 6.7 & 0.73 & 2.0 & 1.13 & 4.0 & 2.61 & 4.8 \\
\hline 4 & 3.8 & 6.0 & 0.70 & 1.0 & 1.00 & 3.0 & 2.42 & 4.0 \\
\hline
\end{tabular}

that the entirely slaked condition in field $\mathrm{C}$ would also apply to an entirely slaked field $\mathrm{A}$, therefore, the totally slaked condition from the right graph in Fig. 6 may be transferred to the left graph. This is indicated by the broken line. Fig. 6 also demonstrates that, for a given field and step of slaking, correlation between $\gamma$ and moisture content was not always satisfactory. Lack of good correlation may be due partly to instrumental errors (radar accuracy is about $1 \mathrm{~dB}$ ) and partly to the way of moisture sampling, which may be not optimal for radar interpretation. Using bulk volumetric moisture content or moisture content by weight instead of clod volumetric moisture content will not give a significant better correlation, because these three measures of moisture content are highly dependent for a given field and step of slaking (Bouten \& Janse, 1979).

- The shape of the curves is entirely determined by the surface relief or roughness. Paying attention to the first step of slaking, it appears that fields $\mathrm{A}$ and $\mathrm{F}$ (ploughing direction parallel to the rails) have curves with a maximum. The positions of the maxima differ for $\mathrm{A}$ and $\mathrm{F}$, which agrees with the fact that these fields are also ploughed differently. Field B (ploughing direction perpendicular to the rails),
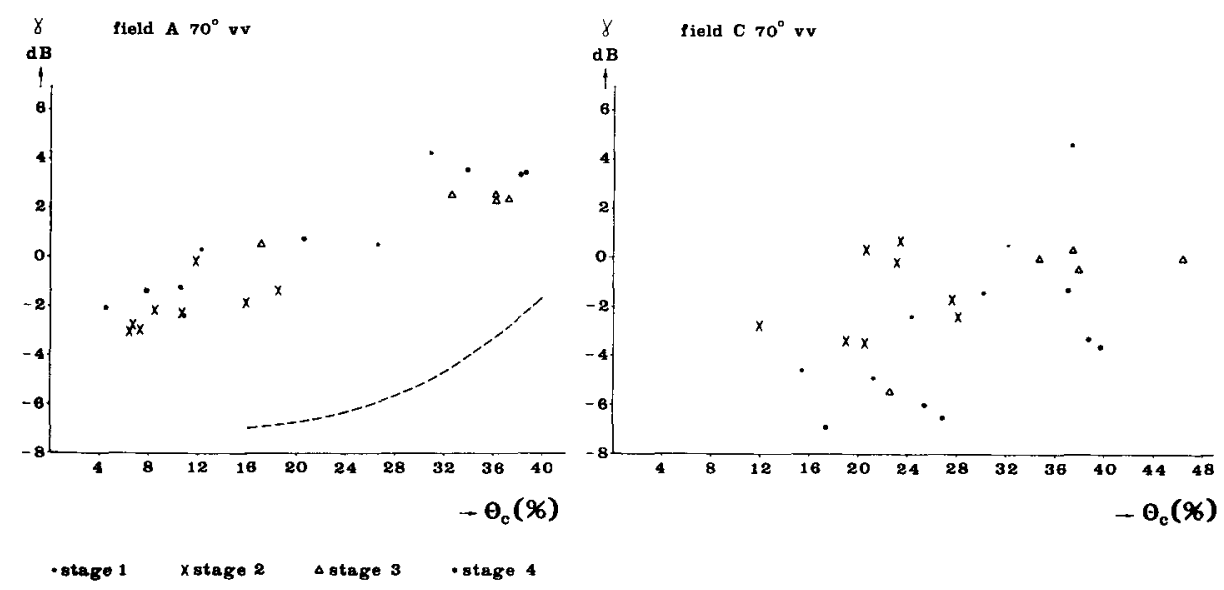

Fig. 6. Backscatter/moisture content relationships for fields $\mathrm{A}$ and $\mathrm{C}$ at the $70^{\circ}$ grazing angle. 
field C (fine seedbed) and field D (rough seedbed) have curves that run upwards more or less monotonously.

- Within each row of graphs, degree of slaking increases from the left to the right. Slaking (being actually a change in roughness) is also reflected in curve shape, namely as a bending upwards of the right parts of the curves. The more slaking, the more bending upwards of the curves. Field $\mathrm{E}$ had been already much slaked in step 1 , and, consequently, bending upwards of the right curve parts can already been seen in the first step.

It appears that many moisture content-roughness combinations are possible at one arbitrary $\gamma_{\mathrm{VV}}$ value and grazing angle, so that hardly any discrimination can be attributed to a single $\gamma$ value. Discrimination is not much better if $\gamma_{\mathrm{VV}}$ is given for two different grazing angles. Even if the entire curve of $\gamma_{\mathrm{VV}}$ versus grazing angle is given, it is not possible to distinguish alle roughnesses that were present in the experiment (for instance: discrimination among B, C, and D is very difficult for step 1). This demonstrates a basic problem of the radar, namely the problem that the radar cannot discriminate all roughnesses and moisture contents that occur in agricultural practice.

On the other hand, it can already be seen from the measuring results that mapping of bare soil surface roughness and moisture content by radar will be possible under certain conditions. Such conditions may be:

- availability of additional information, for instance from a conventional mapping, or from knowledge of agricultural practice in the area under consideration;

- Occurrence of only a few roughness types in the area to be mapped.

- Aiming only at moisture detection, in areas of stable soils (structure change is minimal in stable soils).

- Aiming at a specific problem. For instance, mapping of slaking may be done by determining the difference between $\gamma$ measurements at a large and a small grazing angle. If determination of that difference is repeated, the change in that difference will reflect the change in the degree of slaking.

Furthermore, it may be true that some grazing angle exists for which $\gamma$ is rather insensitive to roughness (de Loor, 1979; Bouten \& Janse, 1979), and is thus suitable for roughness mapping or moisture mapping, respectively. Discovering such a grazing angle from the huge amount of measuring data requires a computer. Such analyses are being carried out. Also, measuring programs are planned for other and/or more radar wavelengths, with improved sampling of moisture and roughness.

\section{Acknowledgments}

The authors are grateful to Ir E. P. W. Attema and Dr Ir G. P. de Loor for their help in preparing this paper. Dr Ir A. R. P. Janse highly stimulated the poject.

\section{References}

Attema, L. P. W., 1978. The radar signature of natural surfaces and its application in active 
microwave remote sensing. In: T. Lund (Ed.), Surveillance of environmental pollution and resources by electromagnetic waves. Reidel, Dordrecht, p. 227-252.

Batlivala, P. B. \& F. T. Ulaby, 1977. Feasibility of monitoring soil moisture using active microwave sensing. Tech. Rep. Remote Sensing Lab., Kansas Univ. 264-12 (January).

Bernacki, H., J. Haman \& Cz. Kanafojski, 1972. Agricultural machines. Theory and construction, Vol. 1. U.S. Department of Commerce, National Technical Information Service, Springfield, Virginia.

Boekel, P., 1976. Possibilities for improvement of structure of fine-textured soils. Med. Fac. LandbWet. Rijksuniv. Gent 41 (1) 79-83.

Boodt, M. de, L. de Leenheer, H. Frese, A. J. Low \& P. K. Peerlkamp, 1967. West-European methods for soil structure determination. State Faculty of Agricultural Sciences, Ghend, Belgium.

Bouten, W. \& A. R. P. Janse, 1979. Radar reflection in relation to slaking. Proc. Workshop Bare Soils (Paris, April 1979). EARSeL, Toulouse.

Davies, D. B., D. J. Eagle \& J. B. Finney, 1972. Soil management. Farming Press, Ipswich, Suffolk.

Kasteren, H. W. J. van \& M. K. Smit, 1977. Measurements on the back scatter of X-band radiation of seven crops, throughout the growing season. NIWARS Publ. No 47. NIWARS, Delft.

Loor, G. P. de, 1976. Radar methods. In: E. Schanda (Ed.), Remote sensing for environmental sciences, Ch. 5. Ecological Series No 18. Springer Verlag, Berlin, etc.

Loor, G. P. de, 1979. Soil moisture determination at X-band. Proc. Workshop Bare Soils Paris, April 1979). EARSeL, Toulouse.

Moore, R. K., 1975. Microwave remote sensors. In: Manual of remote sensing, Ch. 9. American Society of Photogrammetry, Falls Church, Va.

Ulaby, F. T. \& M. Craig Dobson, 1978. Analysis of the active microwave response to soil moisture, Part I: Bare ground. IEEE Trans. Geosci. Electronics GE-16: 286-295. 